\title{
Unified Voice and Group Agency: Developing Teams to Transform Engineering Education
}

\begin{abstract}
Background: Transforming engineering education requires changes that are often too complex and too high-risk for a faculty member to pursue on their own. Teams offer the advantage of combining the skill sets of many individuals; However, in order to successfully transform engineering education, individual change agents must first come together to form effective and efficient teams.
\end{abstract}

Purpose: Drawing together organizational change literature and social movement research, we introduce the theoretical concepts of unified voice and group agency as central to the process of team formation. We analyze how a sample of change teams with academic engineering have worked to build unified voice and group agency within their respective teams throughout the early years of their projects.

Design/Method: This analysis of team formation emerges from our participatory action research with recipients of the NSF Revolutionizing Engineering Departments (RED) grants, utilizing longitudinal qualitative data from focus group discussions with twelve RED teams at the beginning and midpoints of their projects.

Results: We find that unified voice develops through open communication and respectful dissent, and is more likely to develop when there is a shared commitment and when team members feel they are valued. Interdisciplinary teams with a strong unified voice were able to leverage their credibility and networks to then build a sense of group agency. Developing unified voice and group agency are key processes that not only allow individuals to come together as a change team, they also lay the foundation for the team's success.

Keywords: Institutional Change, Team Formation, Team Development 


\section{Unified Voice and Group Agency: Developing Teams to Transform Engineering Education}

\section{Introduction}

In recent years, there have been numerous calls for the transformation of engineering education. Funding agencies have explicitly addressed the need to support the development of a more diverse workforce, to fund programs that incorporate innovative and inclusive changes to undergraduate curriculum, and to address systemic barriers that have prevented the equitable participation of systemically marginalized groups in STEM. This ongoing trend indicates both the desire for and necessity of significant changes in departments and across institutions that will positively impact future cohorts of engineers. However, transforming engineering education requires changes that are often too complex and high-risk for individuals to pursue on their own (Caldwell, 2003; Hackman \& Edmonson, 2008). Changes to engineering education on a broad, impactful scale requires multiple individuals working together in effective and efficient teams.

Teams offer the advantage of combining the skills and experiences of many individuals, as well as bringing together insider knowledge and external specialist expertise (Caldwell, 2003;

Hackman \& Edmonson, 2008). Teams can foster the credibility, legitimacy, and fairness of the change effort when the team members represent key stakeholders (Hackman \& Edmonson, 2008). In addition, team interactions allow for sensemaking, where team members can use each other as sounding boards, to debrief, and to collaboratively work through challenges (Hackman \& Edmonson, 2008).

While there has been increasing research interest in teams invested in institutional change, few studies have examined how individual change agents come together to form a team (Caldwell, 
2003; Scheidgen, 2019). Yet, team formation processes strongly influence both team functioning and the implementation of change (Hackman \& Edmonson, 2008). Further, the existing organizational change literature on teams has focused on the entrepreneurial context (e.g. Aldrich \& Kim, 2007; Hackman \& Edmonson, 2008; Scheidgen, 2019) while research on the formation of social movement organizations has focused on contexts outside of academia (e.g., Blee, 2012; Dugan \& Reger, 2006). Developing an understanding of how change teams develop within academia is critical for improving our ability to transform engineering education.

We define change teams broadly as a group of individuals who are working together with a common purpose toward a collective goal of transformation (Bercovitz \& Feldman, 2011; Hsu, Weng, Cui, \& Rand, 2016; Katzenbach \& Smith, 1993; Olmstead, Beach, \& Henderson, 2019). The team is not a fixed, static entity; team formation is a process (Melucci, 1995; Scheidgen, 2019; Vanaelst et al., 2006) during which members co-create a shared definition of the team that includes a sense of solidarity with teammates (Brubaker \& Cooper, 2000; Dugan \& Reger, 2006) and a shared vision for change with external stakeholders (Doten-Snitker, Margherio, Litzler, Ingram, \& Williams, 2020; Katzenbach \& Smith, 1993; Melucci, 1995). In this paper, we introduce and examine two concepts that are critical mechanisms in the process of team formation: unified team voice and group agency.

\subsection{Unified Voice and Group Agency}

In this section, we draw together organizational change literature and social movement research. We first introduce the concepts foundational to unified voice (vision, shared purpose, common goals, and cohesive voice), before defining and delineating the concept of unified voice. Next, 
we explore two theoretical concepts underlying group agency: group potency and collective efficacy. After defining group agency, we introduce our research questions.

Research on organizational change has found that one of the first tasks of a change team is establishing a clear vision for their projects, shared by all team members, as it is integral to every step of the change process that follows (Hackman \& Edmonson, 2008; Kotter, 1996). Central to this vision is establishing a shared purpose, in which team members share similar understandings of the work that they are undertaking and why they are pursuing these changes (Carson, Tesluk, \& Marrone, 2007). Teams need to then translate their shared purpose into specific and measurable performance goals and develop methods to assess their progress in order to achieve impactful outcomes (Katzenbach \& Smith, 1993). Clear goals facilitate communication and constructive conflict, where team members can focus on how to achieve (or change) their goals and focus on getting results (Katzenbach \& Smith, 1993).

Similarly, research on social movement organizations has stressed the importance of developing a cohesive voice, defined as the articulation of a group's shared purpose (Dugan \& Reger, 2006). In a study of four social movement organizations, Dugan and Reger (2006) find two mechanisms that promote the development of voice: external messaging and internal avenues of expression. Similar to the organizational change literature, the research on social movement organizations stresses the importance of developing a shared purpose. In order to create external messaging, a team must first come to a consensus around their shared purpose, so that they can then communicate this purpose to external stakeholders. To do so, team members must engage in internal avenues of expression, including constructive conflict during which dissenting opinions 
are heard and a variety of ideas are incorporated into a vision shared by all team members (Dugan \& Reger, 2006).

In a study of how team composition impacts team performance within academia, Bercovitz and Feldman (2011) note that while diversity of expertise across team members leads to more innovative teams, it may also increase communication costs due to disciplinary differences in semantics. However, the creative benefits of teams with more unique combinations of knowledge outweighed these increased costs (Bercovitz \& Feldman, 2011). These findings suggest the importance of internal avenues of expression that allow teams to engage in cross-disciplinary communication and develop shared understandings that bridge differences in expertise and backgrounds. When teams are willing to sacrifice some degree of effectiveness early in their efforts in order to spend time strengthening communication with one another, they can cultivate a sense of group identity and have the potential to perform better long-term. This leads to a greater sense of unity which Tilly (1993) notes is an important indication of sustained change in social movements that will endure beyond the specific movement's activities.

We define unified voice as a team's internal vision, shared purpose, and common goals. Unified voice is a key component of a team's organizational character or collective identity--the sense of self developed by change teams of who they are as a group (Blee, 2012; Melucci, 1995). Unified voice is internal to the change team, consisting of the vision, purpose, and goals that are shared by team members. This is in contrast to shared vision, which the change literature defines as a vision for change shared between change teams and external stakeholders (Doten-Snitker, Margherio, Litzler, Ingram, \& Williams, 2020; Henderson, Finkelstein, \& Beach, 2010). 
According to Dugan and Reger (2006), groups have a better chance of achieving their goals if members are able to create a unified voice by "articulat[ing] a unified sense of purpose and direction" (p. 469).

In order to successfully create change, teams must not only develop a unified voice, but also develop a sense of group agency. The concept of group agency builds on prior research on both group potency and collective efficacy, expanding these concepts with an action-orientated lens. Here we delineate each of these concepts before outlining our definition of group agency.

Group potency is a broad, general belief in a group or team's ability to be effective (Blee, 2012; Guzzo, Yost, Campbell, \& Shea, 1993; van Emmerik, Jawahar, Schreurs, \& De Cuyper, 2011). This belief is shared among team members and spans across many tasks and situations (Guzzo et al., 1993), meaning that teams with a strong sense of group potency will likely feel that they can succeed regardless of context. Prior research on group potency has shown that it is positively correlated with overall performance of a group or team (Lee, Tinsley, \& Bobko, 2002; Shelton, Waite, \& Makela, 2011; Stajkovic, Lee, \& Nyberg, 2009). In a study of organizational behavior within student groups, Lee, Tinsley, and Bobko (2002) found that generalized confidence in the group was a strong predictor of success, even when tasks were new or unfamiliar to them. For groups to perform well, it is important that they first establish a mutual belief that they can succeed no matter the circumstances.

First defined by Bandura (1982), collective efficacy refers to the belief in a group or team's effectiveness in completing specific tasks (Gibson, 1999; Guzzo, Yost, Campbell, \& Shea, 1993; 
Kunnari, Ilomäki, \& Toom, 2018; Stajkovic, Lee, \& Nyberg, 2009; van Emmerik, Jawahar, Schreurs, \& De Cuyper, 2011). In a meta-analysis, Stajkovic, Lee, and Nyberg (2009) note a great deal of definition ambiguity between the two concepts of collective efficacy and group potency; based on the prior literature, they delineate collective efficacy as linked to specific domains, while group potency as linked to any task the group might take on. Similarly, van Emmerik, Jawahar, Schreurs, and De Cuyper (2011) define efficacy as task-specific and group potency as broad confidence. Collective efficacy has been shown to have an even stronger positive correlation with group performance than group potency (Stajkovic, Lee, \& Nyberg, 2009). Stajkovic, Lee, and Nyberg (2009) note that a group's collective efficacy influences whether the group initiates action, the degree of effort the group exerts, and the length of time that effort is exerted. Both group potency and collective efficacy are ongoing processes rather than end-states, in which teams evaluate their performance over time; these evaluations in turn impact group performance, which then influences subsequent outcomes (van Emmerik, Jawahar, Schreurs, \& De Cuyper, 2011).

Building on the concepts of group potency and collective efficacy, we define group agency as action-oriented empowerment based on a shared belief among team members of the team's ability to successfully perform tasks and achieve goals. That is, group agency moves beyond a belief in both broad and task-specific capabilities to an empowerment to take action based on those beliefs (Bandura, 2000; Dugan \& Reger, 2006; Hökkä, Rautiainen, Silander, \& Eteläpelto, 2019), reflecting a future-orientation toward institutional change. Group agency arises from shared team experiences (Lorimer, Knight, \& Shoveller, 2020), and is an ongoing process in which team members perceive their goals as attainable and their efforts as worthwhile (Dugan \& 
Reger, 2006) and are motivated by these beliefs to take action. Teams have a better chance of developing group agency and achieving their goals when they engage in ongoing, collective communication; team members must also trust one another enough to engage in risk-taking and clear communication (Dugan \& Reger, 2006).

While group agency is dependent upon processes internal to the team, such as trust, risk-taking, and clear communication, it also emerges from processes external to the team. Group agency may be achieved in part through the cultivation of credibility. Credibility reflects the extent to which teams are respected by others within the institution (Kotter, 1996). According to Kotter's (1996) eight step change model, credibility is necessary so that the teams' ideas and change efforts will be taken seriously by others. Cultivating credibility and being taken seriously by external stakeholders will likely influence a team's collective efficacy and motivation to take action.

In this analysis, we explore the early stages of team formation as experienced by change agents funded through the NSF Revolutionizing Engineering Departments grant mechanism (described below). Much of the prior research related to unified voice and group agency has been based on organizational change teams in industry and social movement organizations. As Olmstead, Beach, and Henderson (2019) argue, research on change teams must be domain-specific, due to the influence of institutional context. Thus, we analyze the concepts of unified voice and group agency specifically within engineering and computer science higher education. In addition, prior research tends to be cross-sectional or retrospective in nature, whereas our research design allows for longitudinal analysis. Specifically, the research questions guiding this paper are: 
1. How do change teams develop unified voice and group agency over time?

2. What factors are most salient in the development of unified voice and group agency?

\section{METHODS \& DATA}

\subsection{Setting: Revolutionizing Engineering Departments (RED)}

This analysis of unified voice and group agency emerges from our participatory action research with the NSF Revolutionizing Engineering Departments (RED) teams to investigate the change process within engineering and computer science higher education. The RED funding mechanism is designed to support awardees in creating systemic change both to advance equity and inclusion within educational environments and to improve the professional development of students with a focus on the middle years of college. NSF requires that teams are multidisciplinary, including instructional faculty, education researchers, social science experts or organizational change experts ${ }^{1}$, and administrators (e.g., the department head or college dean).

As of 2021, NSF has awarded 26 RED grants to 24 institutions. Awarded institutions include both public and private schools with student populations ranging from over 4,000 to over 67,000 . While the currently funded projects range in scope from one department to an entire college, the majority of RED projects focus on one department and include the following areas: chemical, biological, civil, environmental, electrical, mechanical, computer, biomedical, and aerospace engineering, as well as computer science. All RED teams share overarching goals related to transforming engineering education, while teams' change-making processes vary. For example,

\footnotetext{
1 The NSF grant solicitations in 2014, 2015, and 2016 required the inclusion of a social science expert on each team. There was no solicitation in 2017, and in 2018 the solicitation requirement was modified and from then on has required an organizational change expert instead of a social science expert.
} 
one computer science-focused project from a large public institution integrates courses for undergraduates to develop industry-relevant professional skills. Another project at a smaller private institution mobilizes its focus on identity and inclusion by integrating experiential learning opportunities and implementing reflection portfolios for students to assess their own engineering identities.

In addition to funding the RED teams, NSF has also funded RED Participatory Action Research (REDPAR), to support the work of RED teams and to conduct research with the RED teams on the process of change in academia. Our work as REDPAR investigates research questions related to systemic change projects while also supporting connections across teams and providing customized change-making curriculum. The curriculum is designed to cultivate RED team members as change agents and to support their efforts to transform their departments and colleges. We facilitate monthly virtual calls and an annual in-person meeting for the consortium of RED teams where team members work together on activities designed to foster changemaking skills.

\subsection{Data Collection}

In the first year of their RED grant, each team is invited to participate in a baseline focus group with REDPAR researchers; in the third year of their RED grant, each team is invited to participate in a midpoint focus group. Focus group discussions are conducted via video conference and/or telephone call and last for approximately 60 minutes each; each focus group discussion consists of one RED team. This paper utilizes data from the second and third cohorts of RED teams' focus group discussions at both the baseline and midpoint of their projects. While 
there are 13 total teams in the second and third cohorts, only 12 completed discussions at both the baseline and midpoint. To allow for longitudinal analysis, we have omitted the data from one team that only participated in a midpoint focus group. Focus groups ranged in size from 2 to 10 participants, with an average of 5 participants. Baseline focus groups were designed to gather information on the initial stages of their change projects while midpoint focus groups discussed implementation of their plans, adaptations that were made, and the skills utilized to create change.

As a qualitative method of data collection, focus groups center participants' voices and allow for assessment of group dynamics. During focus groups, participants must interact, and researchers can ask participants to compare their perspectives (Morgan 1996); being able to observe communication among team members aided in answering our research questions regarding the development of unified voice and group agency. Both focus group protocols were structured to explore RED teams' progress on their change projects and their engagement with the RED consortium. Questions were generally open-ended (e.g., "How has your project matured or changed since you started?" "What skills have helped you move the project forward?") and linked to probes (e.g., "What parts of change work have you felt underprepared for?") prior to data collection. Participants were given the opportunity at the end of their discussions to provide any additional information they felt was relevant. Focus group discussions were recorded and transcribed, and participants were given access to the data generated by their team's discussion. To help ensure confidentiality, transcripts were anonymized prior to data analysis.

\subsection{Data Analysis}


This research relies on a grounded theory (Glaser \& Strauss, 1967) approach to data analysis. Grounded theory is a qualitative research methodology that centers participants' perspectives and allows the researcher to generate concepts from the data, rather than trying to fit the data within an existing theoretical model (Case \& Light, 2011; Holton, 2008). A grounded theory approach is advantageous for projects that seek to discover processes and relationships between concepts that may be unexplained or unconnected in prior research (Case \& Light, 2011).

To perform our analysis, focus group transcripts were loaded into Dedoose qualitative software; we applied open coding, selective coding, and theoretical coding to analyze the data (Hernandez, 2009; Holton, 2007). Open coding occurs in the initial phases of analysis during which the researcher sticks close to the data, constructing simple codes to capture what is occurring in the data (Thornberg \& Charmaz, 2014). After initial coding, codes were refined and organized into core categories that were developed in relation to relevant literature. While some argue that this approach to data analysis should occur prior to reviewing the literature (Glaser \& Strauss, 1967; Corbin \& Strauss, 1990; Holton, 2008), others have suggested the pragmatic benefits of moving between the data and extant theory (Lempert, 2007; Timmermans \& Tavory, 2012). Following this latter approach, our use of grounded theory relies on comparison with the literature to best identify gaps in theorizing and to make valuable contributions to current theoretical conversations.

Once substantive codes were determined, selective coding was performed. Selective coding reflects the process of coding only to variables related to core categories (Holton, 2008). Developing categories requires constant comparison between codes (Thornberg \& Charmaz, 
2014). Our coding scheme includes the following core categories: unified voice, group agency, organizational character, emotional investment, interpersonal rapport, and the role of the RED consortium. For the purpose of this paper, we focus primarily on unified voice and group agency, taking into consideration where and when codes within these two categories intersect with codes within the other categories as well as how the codes inform one another. This reflects our implementation of theoretical coding; theoretical codes reference pre-existing theories that can be used to describe the relationships between categories (Thornberg \& Charmaz, 2014).

Throughout the process of data analysis, memo-writing was used to identify emergent themes and explicate findings (Charmaz \& Belgrave, 2007; Lempert, 2007). Memos served as flexible tools for recording researchers' interpretations of the data over time and aided in the development of a narrative from the data (Lempert, 2007). Memo writing was performed by one researcher throughout the various stages of coding and memos were then annotated and expanded upon by a second researcher. Collaborative processes of documentation and analysis enable more open communication within the research team, thus strengthening researchers' abilities to co-construct meaning and develop theory (Walther et al., 2017).

\section{FINDINGS}

This section presents findings generated through our analysis of baseline and midpoint focus group discussions with RED teams, exploring how these change teams developed unified voice and group agency over time. The findings also speak to the factors that are most salient in the development of unified voice and group agency. 


\subsection{Unified Voice}

Our findings indicate that RED teams began to develop unified voice during the proposal writing process as team members designed their change projects. Unified voice was strengthened over continuous dialogue after the grant was awarded. Through internal avenues of expression (e.g., constructive conflict, ongoing negotiations, admissions of uncertainty), teams could come to a consensus on their group identity. As teams solidified group cohesion, they could then communicate their sense of "groupness" to stakeholders through external messaging and the construction of a unified "we."

The process of developing unified voice began during proposal writing when teams built their vision for their respective projects and decided to what extent they would delineate responsibilities. While many teams incorporated the ideas of multiple team members during proposal writing, the majority of RED teams had one individual leading the proposal development process who exerted the final say in the vision for change that was presented in the proposal. For example, one PI described this process as:

Well, you know when you write a proposal, somebody has to take the lead. From the ideas that came out, let's say someone had talked about the importance of entrepreneurship, and I asked that person to submit a section, and I had to tone it down.

One person talked about using a strand as a way of looking at competency, so I had him submit a section on that. So, it was mainly having people submit and write a particular section, and we try to make sense of it ... It was really collaborative.

Once someone took the lead, individual team members were called upon to contribute their expertise in shaping the team's proposal. A Co-PI from another team similarly said, 
You know how it goes with proposals, right? One person needs to essentially champion it to make sure it gets done on time, but it takes a whole village, it takes 20 different people to come together, bring ideas to put the whole thing together.

By involving multiple people in proposal development, team members are able to contribute in a meaningful way to the overall vision for the project. However, the writing process employed by these teams, in which one individual was responsible for integrating ideas from their team members, limited the development of building a unified voice at this early project stage as the team members were not involved in directly negotiating with one another their vision for the project.

In contrast, three teams involved multiple team members in developing a vision for their respective projects during the proposal writing process. One Co-PI noted that they "threw around ideas" with another team member, and after determining who to include as part of their team, they brought in the "core team" to collaboratively write the proposal. For another team that involved multiple people at this stage, their unified voice within the team translated to the way they approached their project in relation to the rest of the department. The PI said:

Of course, we want all the people in the department to be members of the team but it's limited...but the way we market this in the department is really the grant. Everybody is part of this grant. Some people may be on the grant officially as faculty or senior personnel but the way that we have it is it's really going to the department. And then [our social scientist] and [our education researcher], they're helping us and our faculty are going to be more receptive to their ideas as opposed to some outside person saying we need to change or this is the right direction to go. 
This quotation points to how this team worked collaboratively to establish a unified voice early on; they approached their project as something that is shared among the team, while taking into consideration the impact their project will have on the rest of the department. Other faculty members may be "more receptive" if the team is able to communicate a cohesive vision for their project.

As their projects progressed, RED teams continued to develop a unified voice through ongoing communication and sense-making about the vision of their change projects. One social scientist explained at the midpoint focus group:

A lot of people in this department came to the field without having degrees in it. [There's] a lot of sense-making. What is this field and what are we doing? And really earnestly caring about designing something that will work for the long run and fit the departments. I think [that our RED project is] giving people a forum for having this kind of conversation, because we are usually focused on research and grants and things like that and we're less often coming together around these kinds of issues, and just generating a forum where people could say this matters a lot and this has a huge impact of our work on our field and on the world.

They went on to remark that they felt everyone on the team was "super interested and excited about generating a curriculum," an indication of a commitment to a common goal. As this data suggests, both team members and department faculty benefitted from having an open forum for conversations dedicated to their visions for institutional change, as this communication allowed individuals to develop a shared sense of commitment to their projects. 
Teams also negotiated their sense of group cohesion through constructive conflict. At the midpoint focus group, a Co-PI discussed how their team navigated conflict as they continued to work together:

To me, it's fascinating that our team is extremely diverse and this has led to many conflicts and challenges in communicating. We are humbled every day by the fact that we're supposedly trying to teach or provide a learning environment for our students to develop their skills, while, at the same time, we have a lot to learn ourselves.

In this case, individual team members' diverse perspectives created tension at times, but these tensions could be worked through as team members cultivated an ongoing dialogue and found ways to learn from one another. This team went on to discuss how their communication conflicts pushed them to engage in shared sense-making which in turn strengthened their development of a unified voice for their project.

At the midpoint focus group, RED teams were asked to give an elevator pitch of their projects. Elevator pitches that were characterized by the clear communication of a relatively brief, cohesive message about the essence of their project that was agreed upon by other team members were interpreted as evidence of a team's unified voice. Seven teams, that did not necessarily feel more confident or more prepared relative to other RED teams at the baseline focus groups, were nevertheless able to demonstrate their unified voice through their elevator pitches at the midpoint. For example, after an engineering educator from one team gave their elevator pitch, the team's social scientist said, "Yeah. That's pretty consistent with what I was thinking." They went on to add a few comments regarding the core of their curriculum change efforts, but ended by saying "I think that's basically just a quick elaboration of what [the engineering educator] 
said." In contrast, two teams at their respective midpoint focus group discussions explained their projects at length, but lacked a clear focus and were not able to articulate an elevator pitch. These teams were generally confident about their team members' expertise and/or the project itself early on, however, this initial confidence did not necessarily lead to a cohesive sense of group identity. Notably, these two teams did not involve multiple people early in the proposal development stage.

Ongoing negotiations around their vision for change led RED teams to come to a consensus among themselves about who they are as a team and to thus develop a unified voice. This in turn allowed for teams to communicate with and influence their department or school. For example, at the time of the midpoint focus group, one Co-PI described:

We now have values, a group of shared values that we didn't have before...in our first retreat that we had that came about because of this initiative, we came up with a shared value statement for the department that all faculty contributed to and signed off on and bought into. So that, I think, certainly changed the context of where we are, almost spelling out what we value and how we want to operate.

This quotation indicates other faculty members' involvement in shaping their department's values statement, the inception of which was initiated by the RED team. By having a clear unified voice, teams could better communicate their values and align themselves with external stakeholders.

While it was important to involve faculty stakeholders, teams also conveyed a sense of "groupness" through their construction of external messages that distinguished "us" from 
"them." In both baseline and midpoint focus groups, teams often identified themselves as distinct from (albeit, still aligned with) faculty stakeholders. "I think part of the revolutionizing is that faculty are going to resist and struggle, because they don't like change, generally," said one PI, reflecting on the initial negative reactions to their team's project. Another team's PI mentioned how they approached engaging with faculty differently, noting:

We are a smaller department compared to the other RED teams. Even when we were writing the proposal, we made sure all the faculty had some kind of input, even though this is the core group that wrote the proposal... When we got funded, we were careful to tell them at faculty meetings what was going on with the study and what we are hoping they will do.

While this quote speaks to broad faculty involvement, the PI frames the team ("we") as active subjects presenting their plans to the faculty ("them") and setting expectations. Teams expressed varying degrees of success in aligning with faculty, but consistently relied on "us vs. them" discourse. The above quotation also touches on contextual factors that shape the team's organizational character. Team members from a "smaller department" may already have a positive rapport with other faculty, and this in turn shapes the way they frame themselves. Regardless of the size of the department, teams aimed to present a cohesive message to connect with faculty members. One Co-PI at a larger institution explained:

I think that we've been very careful to craft our message and make sure that we fully understand the story that we're telling... we're being very conscientious and very clear about the message that we're sending and getting that buy-in early.

Relatedly, a social scientist at another institution said that their team "tried really hard to work with PR. We were very careful about the message that was crafted and what we wanted to send 
out." These efforts to craft external messaging further developed teams' unified voice as the team developed a cohesive message through open communication.

Our data shows how unified voice can emerge at the inception of teams' projects; RED teams that involved multiple people in the proposal writing process were able to establish shared ownership over their project from the beginning and produce succinct elevator pitches a few years later at their midpoint focus group discussions. All teams, including those teams that had a single team member lead the proposal writing, worked toward developing unified voice through ongoing dialogue and the active construction of group identity. For example, in their midpoint focus group, one team's Co-PI reflected on the challenges of working together:

The other critical piece is alignment. People always talk about that and I'm always just like, 'Yeah whatever, it's just leadership speak,' until I've experienced it. I had a vision ...that hasn't changed very much, if at all, but to this day I still feel like not everyone gets it or everyone has different ways. And it's not necessarily that I want everyone to see it my way, but the first step is for each of us to understand what our ways of thinking are.... At the end of the day, you have to have a nice story about where you're headed that gets everybody excited. I feel like we have that, which is cool.

This quotation reflects the process of developing unified voice. While team members may have individual goals for their change projects, they have to find ways to communicate with one another, come to a shared understanding, and be able to articulate that unified voice to external stakeholders. 


\subsection{Group Agency}

In addition to unified voice, focus group discussions revealed the ways in which RED teams established group agency. Speaking to their internal trust, teams highlighted their prior working relationships, open and effective communication, and confidence in shared and individual expertise as integral components of group agency. While, as discussed above, teams built a unified voice by viewing themselves as separate from faculty not on their team (e.g., "us vs. them"), they also aligned themselves with their faculty and established credibility with external actors in order to develop their group agency.

We found that building trust among team members was integral to developing group agency. Many teams were able to draw upon prior working relationships that had already established a foundation of trust. At the baseline focus group, one team's PI said:

[Our social scientist] and I have worked together as long as I've worked with [our other team members]. So that was somebody I felt comfortable with, as well as she has done work in our college on these aspects.

Here, prior working relationships were a driving factor in the initial selection of team members, and feeling "comfortable" with this individual was mentioned before her technical qualifications. A Co-PI on another team mentioned how prior working relationships with some teammates taught them "the importance of team building" and that "working with people you like really matters in change work." This team also acknowledged one another for their strong communication and networking skills, demonstrating team members' senses of their own contributions. 
While the notion of ongoing dialogue has been discussed as essential to developing unified voice, we found that clear communication between team members was also a determining factor of group agency. The same PI who mentioned their prior working relationships at the baseline also remarked upon the team's interpersonal rapport at the midpoint focus group:

We have a great team. No conflicts so far. We all believe in what we are doing. Several of us had not worked together on a research project before, but we've been collaborating for a long time. We've worked on other projects together. We have immense respect for each other. Even if we disagree, we disagree respectfully.

As shown by this quote, confidence in the team was often linked to mutual respect grounded in prior working relationships. These past experiences built a foundation of trust for team members, including trust in their ability to communicate openly with one another; in turn, this fostered their sense of group agency.

Teams that did not have prior working relationships also had the potential to build trust, especially if they first established a sense of who they are as a group and that they are working toward the same goals (i.e., by first establishing unified voice). One PI on a team without prior working relationships reflected on building a positive team dynamic early on in their project:

I think we've just learned to start working together in ways that we've never worked together. That's the true spirit of the community, when you're talking about what can we give... What I see is that people seem to be feeling a part of something bigger than themselves already. Once you have that, that is a tremendous step toward accomplishing anything. 
Another team member also said that "I don't doubt in any way, shape, or form that we have the right people at the table." By recognizing who they are as a team - that they are a "community" made up of the "right people" who have shared commitments - they felt more empowered to create change. On another team that formed through networks, one member said:

When the project started, I think I was ready to make changes in my teaching but without help from [our social scientist], without help on the team, or from the material that my colleagues have developed in terms of worksheets and templates... I don't think I would have done it. So I think the skills, in terms of just putting the different skills together... I think that's what's been the most helpful.

This individual trusted their team members to help and support them in implementing changes in their own teaching, while also indicating the necessity of interdisciplinary contributions. By "putting the different skills together," the team could feel confident working toward collaborative goals.

A few of the RED teams also explicitly credited their PI with establishing effective communication within the team. Acknowledging the leadership style of their PI and how the team has grown together, one individual reflected:

As an outsider to [engineering], being involved in this project was the first time I saw [the PI] working as a leader within her department. Her style is very inclusive. She listens a lot... It's a good team, we work well together. People are working on the aspects they are passionate about... The way we interact with each other and how we've managed to engage faculty--it's not our project, it's everybody's project. 
Through inclusive leadership, listening skills, and the distribution of responsibility, this PI fostered a positive relational dynamic among team members. In turn, team members built a shared sense of ownership over their change project.

RED teams also developed group agency by identifying the technical skills and interpersonal strengths of team members. Reflecting on their progress at the midpoint focus group, one team member described the strengths of their social scientist, stating:

[Our social scientist] has been the nucleus. She really drives the whole thing. She's great at what she does. Questions that we have, how do we want to do this, this is not related to something that we had talked about, she's very supportive and she comes up with solutions.

Another team's engineering educator described their collaboration with the team's social scientist:

I think for me it's just being a part of the department for so long, kind of knowing the culture and when I feel the culture shift, and just kind of being that inside spy almost so that [the social scientist] and I can get together and he can say 'Hey, I noticed this,' and I can say 'Oh, well those people have an ongoing conflict and here's what it is and maybe we can work around it.' I feel like having an outside pair of eyes and an inside pair of eyes that are really just committed to 'let's just get this going and have a good productive conversation' has been really helpful.

This quotation speaks to the benefits of having a diverse team where both insider and outsider perspectives are respected, which can bolster the team's sense of group agency. These acknowledgments were made at the midpoint focus groups, by which time team members were 
able to assess how individual strengths actually contributed to their projects and then feel empowered to take further action.

We found that teams built group agency through confidence in each other's expertise as well as the collective expertise of the team. By the midpoint focus groups, teams could draw on evidence from their experiences working on their RED projects specifically. Beyond the acknowledgment of "outsider" contributions more generally, other individual team members were often explicitly mentioned by name and praised for their abilities to connect with external stakeholders. One PI called out the strengths of three individuals, saying:

That's when [one of the Co-PIs], [our education researcher], and [our social scientist] come into play because I think [the faculty are] going to be more receptive to reaching out to them, talking to them, and also summarizing what students are thinking through the focus group meetings and they can bring back what the students are overwhelmingly saying. This approach is not working for the majority of the students and maybe that presents a strong enough reason to change.

Similarly, a social scientist on another team said of their teammates:

[They] are not small actors in having created an environment where people felt like they could contribute and do interesting things. They're understated heroes in that regard. They're trusted, they're respected, they're occasionally hated, but that happens with any administration. People are confident in the ability of the individuals who are running this project.

As shown in these quotes, individuals were often quick to develop confidence in their team members who already possessed high credibility within their institution, which in turn could 
make them feel that their efforts were worthwhile. That is, seeing how their team members were respected for their competency helped to develop a sense of group agency for many RED teams.

In addition to the role of credibility at the individual-level, credibility of their respective RED projects emerged as a significant factor for developing group agency as teams discussed their relationships with institutional actors. Several teams mentioned that they were able to successfully garner support from the Dean, while also identifying support from faculty, alumni, and advisory boards as relevant for creating change. "I can say for sure that our Dean is very interested," one PI said, continuing:

He listens to the results of our work and would like to have some of our findings picked up by the departments... as we move forward, we will try to emphasize to all our peers what we're doing and how it could possibly benefit them. So we want to make sure that this is more widely used and benefits the whole institution.

Thus, support from administration helped develop this team's group agency, particularly around their ability to propagate their change throughout their institution. All teams discussed their need to align themselves with faculty. "We have to listen to faculty to see where their comfort is with change," a PI from another team explained, "You have to meet them when they are taking baby steps, and prod them to take a larger step in the future." The process of aligning with faculty unfolded over time, even when faculty showed some resistance initially, as another PI said:

I think over time, as we have continued to work on it, and engage people, I've been pleased that...I think almost all faculty, maybe all faculty, care about student success. And maybe at different levels, but they care about student success. Some teams also acknowledged how they incorporated faculty into their projects. For example, one team discussed how "having a different role for everyone in the long run will ensure that this 
project will touch every faculty member." By finding shared values with department faculty and more intentionally including faculty members into the implementation of RED projects, teams could further establish their credibility.

Reflecting on how their group identity has shifted over time, some RED teams stressed the importance of unified voice for building a sense of group agency. One PI explained:

The most important thing here from my perspective as to what I've witnessed is for the first time, at least since I've been here, there really is a feeling of community and all kinds of things happening that were unintended and they're positive, because we're all talking together and we're listening and we're all contributing in different ways. Therefore, we are a lot smarter now than the time when we received the proposal. What we do, what we can do, what we can envision, what we can dream, what we can empower by engaging so many people... To me that rich space is now enabling us to do lots of things, even more than we imagined. That's been the most important thing I have seen. Aside from the proposal, the fact that we are committed to change, and having honest conversations, that in itself has brought an extreme value.

Here, their team established a "feeling of community" by engaging in dialogue. The team not only had "honest conversations," but were also able to reflect on their shared commitments and values, thus creating within their team a unified voice. This process of developing a unified voice has in turn has resulted in a sense of group agency that is enabling them to do "even more than [they] imagined." By developing a unified voice and exploring possibilities for change, RED teams then developed a sense of group agency that empowered them to take action and move forward with their change projects. 


\section{DISCUSSION}

This paper seeks to answer: How do change teams develop unified voice and group agency over time? What factors are most salient in the development of unified voice and group agency? We find that unified voice is important to develop early in a change project, during proposal writing or during the early stages of team formation. Unified voice grows through open communication and respectful dissent, and is more likely to develop when there is a shared commitment and when team members feel they are valued. Interdisciplinary teams with a strong unified voice were able to leverage their credibility and networks to create group agency.

Developing unified voice helps teams construct and communicate a cohesive understanding of who they are and work more effectively through challenges together. When members of RED teams did not collaboratively write the grant proposal, they found it necessary to devote more time at the beginning of their projects to developing a shared sense of purpose for their project. In doing so, they were able to further establish their vision for change; vision-building then continued through ongoing communication and messaging to external audiences. Internal avenues of expression, such as conflict or dissention, are integral to creating a cohesive voice (Dugan \& Reger, 2006).

The RED teams that expressed the greatest confidence in their projects at the beginning did not necessarily develop a stronger sense of group cohesion over time relative to the other teams. This may be because admitting uncertainty early on can help establish a norm of open communication, which then fosters unified voice. When team members feel they can express themselves within the group, they may be more likely to establish a sense of unity. We find that the development of trust and communication was particularly important for those teams that 
could not rely on positive prior collaborations. While diverse perspectives and disciplines within the teams created periodic tensions, these instances could be opportunities for teams to have productive dialogue about their shared commitments. For many RED teams, the development of a unified voice was further strengthened through external messaging, as they articulated a "we" in opposition to a "they" who have different values or interests (Blee, 2012; Dugan \& Reger, 2006).

In order to fulfill the NSF requirements for each team to include an education researcher and social science expert, some teams needed to look beyond their current and prior working relationships. In these instances, teams discussed the importance of finding individuals who had shared commitments and values to improving engineering education. While these individuals thus came to the team without a sense of trust established from prior collaborations, the strategic selection of team members set the foundation for developing unified voice insofar as team members contributed not only their skills, but they also came into the project sharing a sense of purpose and commitment to the change process. Recognizing their shared commitments can strengthen relationships among team members and remind the team of their group's sense of purpose.

The interdisciplinary nature of the RED teams underlaid their efforts to develop a sense of group agency. For some of the RED teams, the inclusion of education researchers and social science experts on their teams gave the engineering team members new, increased exposure to these fields. RED teams found that creating mutual respect was foundational for working across disciplinary differences and productively working through disagreements. Within our focus group discussions, RED teams explicitly praised their fellow team members for their strengths and expertise and highlighted others' contributions. Specific words of affirmation can foster 
group agency as team members feel their individual skills and perspectives are valuable and necessary. When individuals are empowered in this way, they are more likely to perceive their goals as achievable and be motivated to take action (Dugan \& Reger, 2006), thus strengthening their group agency.

For the majority of RED teams, the process of academic change entails a lot of tasks that were unknown and difficult to identify at the outset of their projects. Due to this lack of task specificity, teams were likely to express group potency at the beginning of their projects--a belief that the assembled team could "do anything". We find that as teams engaged in open communication, building trust and mutual respect across disciplines, this group potency developed into collective efficacy (ie, task-specific confidence). Finally, as teams built credibility within their institutions and achieved small wins, their group potency and collective efficacy developed into a sense of group agency.

Interdisciplinary teams can increase their efficacy by learning from one another and leveraging networks that would not necessarily be otherwise available to them (van Emmerik, Jawahar, Schreurs, \& Cuyper, 2011). That is, by including members from outside of their core engineering departments, RED teams can benefit from alternative approaches to research, curriculum development, and program evaluation, and connections to wider networks. Teams can have greater potential for long-lasting change if they are able to garner credibility through connections with a wide range of stakeholders. Further research is needed to investigate the potentially causal nature of the relationship between unified voice and group agency.

Our findings here suggest that unified voice may lead to the development of group agency (see Figure 1). By building a unified voice, the RED teams built a sense of community and 
established patterns of effective communication. This in turn built their confidence in their ability to achieve their goals. As team members feel empowered in their individual roles and feel positively about their relationships with whom they are working, teams can more easily envision a path toward greater equity within their institutions.
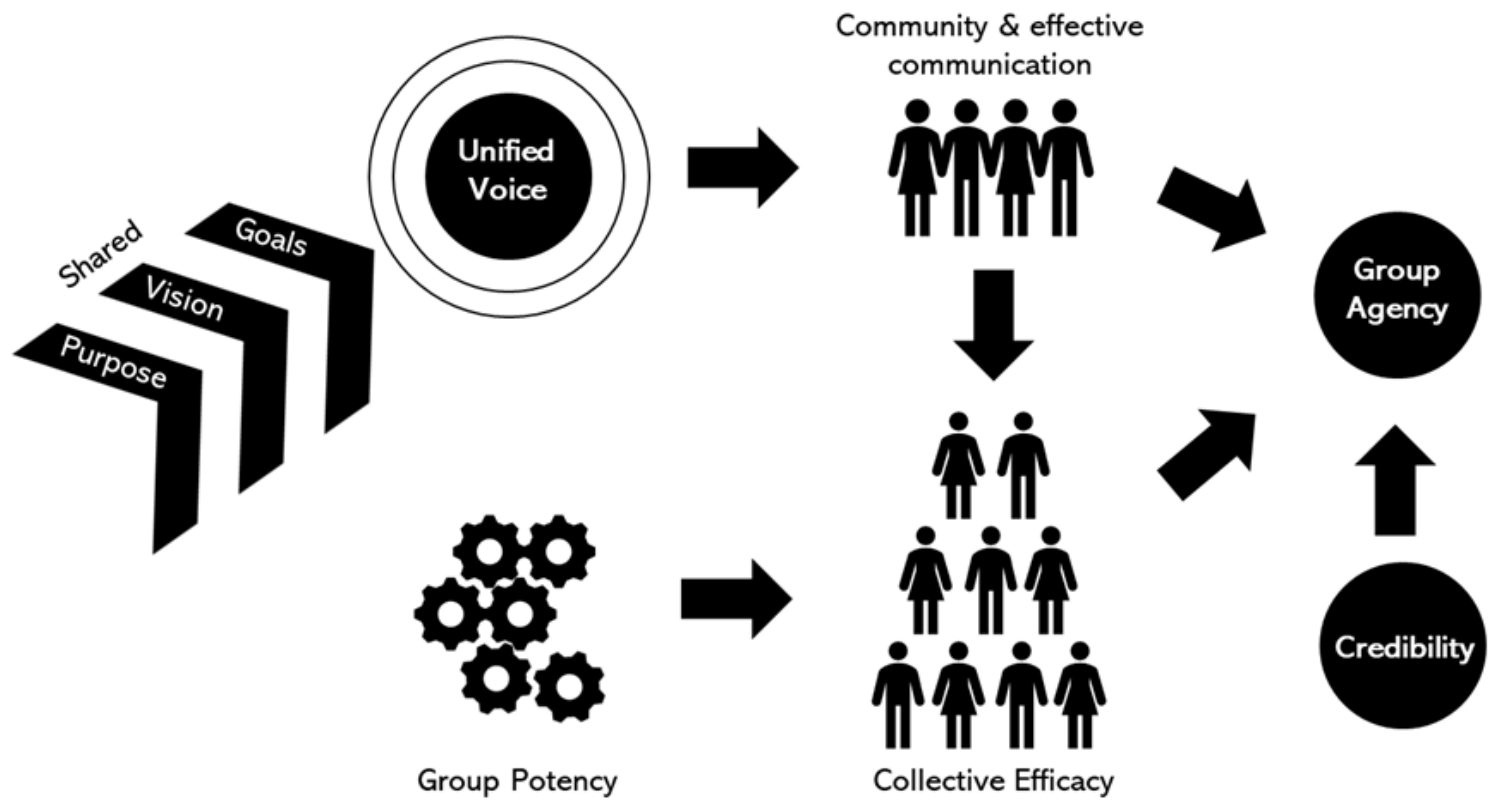

Figure 1. Connecting the development of unified voice and group agency in team formation

There are some limitations to our research that may be points of departure for other studies of teams working to transform their institutions. It is unclear whether these findings focused on engineering and computer science academic change will also transfer to other academic disciplines, although we expect similar processes to take hold. Additionally, since this research focuses on two time points approximately two and a half years apart, we are only able to address unified voice and group agency in the relatively early years of change projects. With our results, we cannot determine whether unified voice and group agency shift and change after the first few years of a change project. Finally, some teams have experienced significant turnover of team 
members over the duration of their projects, but it is unclear the extent to which shifts in the actual makeup of teams impacts unified voice and group agency. The questions we asked in our focus group protocol did not allow us to examine the impact of personnel transitions during the course of the project.

By bringing together organizational change literature and research on the formation of social movements, we have identified two concepts central to the process of the formation of change teams. Developing unified voice and group agency are key processes that not only allow individuals to come together to form a change team, they also lay the foundation for the team's

success. Unified voice and group agency are both central to effectively communicating change to stakeholders and instituting transformation of engineering education.

\section{Acknowledgements}

This research was supported by a grant from the National Science Foundation [blinded for review]. Any opinions, findings, conclusions, or recommendations expressed in the material are those of the authors and do not necessarily reflect those of the National Science Foundation. The author team would like to thank the RED teams for their time and effort in providing us with constructive feedback. 


\section{REFERENCES}

Baillie, C., Pawley, A., and Riley, D. (Eds.). (2012). Engineering and social justice: In the university and beyond. Lafayette, IN: Purdue University Press.

Bandura, A. (1982). Self-efficacy mechanism in human agency. American psychologist, 37(2), 122. https://doi.org/10.1037/0003-066X.37.2.122

Bandura, A. (2000). Exercise of human agency through collective efficacy. Current directions in psychological science, 9(3), 75-78. https://doi.org/10.1111/1467-8721.00064

Bercovitz, J., \& Feldman, M. (2011). The mechanisms of collaboration in inventive teams: Composition, social networks, and geography. Research Policy, 40(1), 81-93. https://doi.org/10.1016/j.respol.2010.09.008

Blee, K. M. (2012). Democracy in the making: How activist groups form. New York, NY: Oxford University Press.

Brown, A. M. (2017). Emergent strategy. Chicao, CA: AK Press.

Brubaker, R., \& Cooper, F. (2000). Beyond "identity." Theory and Society, 29(1), 1-47. https://doi.org/10.1023/A:1007068714468

Caldwell, R. (2003). Models of change agency: a fourfold classification. British Journal of Management, 14(2), 131-142. https://doi.org/10.1111/1467-8551.00270

Carson, J. B., Tesluk, P. E., \& Marrone, J. A. (2007). Shared leadership in teams: An investigation of antecedent conditions and performance. Academy of management Journal, 50(5), 1217-1234. https://doi.org/10.5465/amj.2007.20159921

Case, J. M., \& Light, G. (2011). Emerging research methodologies in engineering education research. Journal of Engineering Education, 100(1), 186-210. https://doi.org/10.1002/j.21689830.2011.tb00008.x

Charmaz, K., \& Belgrave, L. L. (2007). Grounded theory. In Ritzer, G. (Ed.) The Blackwell Encyclopedia of Sociology. Malden, MA: Blackwell Publishing.

Corbin, J. M., \& Strauss, A. (1990). Grounded theory research: Procedures, canons, and evaluative criteria. Qualitative sociology, 13(1), 3-21. https://doi.org/10.1515/zfsoz-1990-0602

Doten-Snitker, K., Margherio, C., Litzler, E., Ingram, E., \& Williams, J. (2020). Developing a shared vision for change: Moving toward inclusive empowerment. Research in Higher Education, 1-24. https://doi.org/10.1007/s11162-020-09594-9

Dugan, K., \& Reger, J. (2006). Voice and agency in social movement outcomes. Qualitative Sociology, 29(4), 467-484. https://doi.org/10.1007/s11133-006-9036-7 
Gibson, C. B. (1999). Do they do what they believe they can? Group efficacy and group effectiveness across tasks and cultures. Academy of Management Journal, 42(2), 138-152. https://doi.org/10.5465/257089

Glaser, B. G. \& Strauss, A. L. 1967. The discovery of grounded theory. Chicago: Aldine.

Guzzo, R. A., Yost, P. R., Campbell, R. J., \& Shea, G. P. (1993). Potency in groups: Articulating a construct. British journal of social psychology, 32(1), 87-106. https://doi.org/10.1111/j.20448309.1993.tb00987.x

Hackman, J. R., \& Edmondson, A. C. (2008). Groups as agents of change. In Cummings, T. G. (Ed.), Handbook of organization development, (pp. 167-186). Thousand Oaks, CA: Sage Publications.

Henderson, C., Finkelstein, N., and Beach, A. (2010). Beyond dissemination in college science teaching: An introduction to four change strategies. Journal of College Science Teaching, 39(5), $18-25$.

Hernandez, C. A. (2009). Theoretical coding in grounded theory methodology. Grounded Theory Review, 8(3).

Hökkä, P., Rautiainen, M., Silander, T., \& Eteläpelto, A. (2019). Collective AgencyPromotingLeadership in Finnish Teacher Education. In J. Murray, A. Swennen, \& C. Kosnik (Eds.), International Research, Policy and Practice in Teacher Education : Insider Perspectives (pp. 15-29). Cham: Springer.

Holton, J. A. (2007). The coding process and its challenges. The Sage handbook of grounded theory, 3, 265-289.

Holton, J. A. (2008). Grounded theory as a general research methodology. The grounded theory review, 7(2), 67-93.

Hsu, S. C., Weng, K. W., Cui, Q., \& Rand, W. (2016). Understanding the complexity of project team member selection through agent-based modeling. International Journal of Project Management, 34(1), 82-93. https://doi.org/10.1016/j.ijproman.2015.10.001

Katzenbach, J. R., \& Smith, D. K. (1993). The discipline of teams. Harvard Business Review, 83(7), 162.

Kotter, J. P. (1996). Leading Change. Boston, MA: Harvard Business School Press. 
Kunnari, I., Ilomäki, L., \& Toom, A. (2018). Successful teacher teams in change: The role of collective efficacy and resilience. International Journal of Teaching and Learning in Higher Education, 30(1), 111-126. http://hdl.handle.net/10138/235308

Lee, C., Tinsley, C. H., \& Bobko, P. (2002). An Investigation of the Antecedents and Consequences of Group-Level Confidence 1. Journal of Applied Social Psychology, 32(8), 16281652. https://doi.org/10.1111/j.1559-1816.2002.tb02766.x

Lempert, L. B. (2007). Asking questions of the data: Memo writing in the grounded theory tradition. The Sage Handbook of Grounded Theory, 245-264.

Long III, L., \& Mejia, J. A. (2016). Conversations about diversity: Institutional barriers for underrepresented engineering students. Journal of Engineering, 105(2), 211.

https://doi.org/10.1002/jee.20114

Lorimer, K., Knight, R., \& Shoveller, J. (2020). Improving the health and social wellbeing of young people: exploring the potential of and for collective agency. Critical Public Health, 1-8. https://doi.org/10.1080/09581596.2020.1786501

Melucci, A. (1995). The process of collective identity. In Johnston, H. \& Klandermans, B. (Eds.) Social Movements and Culture, (pp. 41-63). Minneapolis, MN: University of Minnesota Press.

Morgan, D. L. (1996). Focus groups. Annual review of sociology, 22(1), 129-152. https://doi.org/10.1146/annurev.soc.22.1.129

Olmstead, A., Beach, A., \& Henderson, C. (2019). Supporting improvements to undergraduate STEM instruction: an emerging model for understanding instructional change teams.

International Journal of STEM Education, 6(1), 20. https://doi.org/10.1186/s40594-019-0173-4

Riley, D. (2008). Engineering and social justice. Synthesis Lectures on Engineers, Technology, and Society, 3(1), 1-152.

Scheidgen, K. (2019). Social Contexts in Team Formation. Historical Social Research/ Historische Sozialforschung, 44(4 (170), 42-74. https://www.jstor.org/stable/26804866

Shelton, P. M., Waite, A. M., \& Makela, C. J. (2010). Highly effective teams: A relational analysis of group potency and perceived organizational support. Advances in Developing Human Resources, 12(1), 93-114. https://doi.org/10.1177/1523422310365665

Stajkovic, A. D., Lee, D., \& Nyberg, A. J. (2009). Collective efficacy, group potency, and group performance: meta-analyses of their relationships, and test of a mediation model. Journal of applied psychology, 94(3), 814. https://doi.org/10.1037/a0015659

Theobald, E. J., Hill, M. J., Tran, E., Agrawal, S., Arroyo, E. N., Behling, S., ... \& Freeman, S. (2020). Active learning narrows achievement gaps for underrepresented students in 
undergraduate science, technology, engineering, and math. Proceedings of the National Academy of Sciences, 117(12), 6476-6483. https://doi.org/10.1073/pnas.1916903117

Thornberg, R., \& Charmaz, K. (2014). Grounded theory and theoretical coding. The SAGE handbook of qualitative data analysis, 5, 153-69.

Tilly, C. (1993). Social movements as historically specific clusters of political performances. Berkeley Journal of Sociology, 38, 1-30. https://www.jstor.org/stable/41035464

Timmermans, S., \& Tavory, I. (2012). Theory construction in qualitative research: From grounded theory to abductive analysis. Sociological theory, 30(3), 167-186.

https://doi.org/10.1177/0735275112457914

Vanaelst, I., Clarysse, B., Wright, M., Lockett, A., Moray, N., \& S'Jegers, R. (2006).

Entrepreneurial team development in academic spinouts: An examination of team heterogeneity. Entrepreneurship Theory and Practice, 30(2), 249-271. https://doi.org/10.1111/j.1540$\underline{6520.2006 .00120 . x}$

van Emmerik, H., Jawahar, I. M., Schreurs, B., and De Cuyper, N. (2011). Social capital, team efficacy and team potency: The mediating role of team learning behaviors. Career Development International, 16(1), 82-99. https://doi.org/10.1108/13620431111107829

Walther, J., Sochacka, N. W., Benson, L. C., Bumbaco, A. E., Kellam, N., Pawley, A. L., \& Phillips, C. M. (2017). Qualitative research quality: A collaborative inquiry across multiple methodological perspectives. Journal of Engineering Education, 106(3), 398-430.

https://doi.org/10.1002/jee.20170 